\title{
TWENTY YEARS OF ANAESTHESIA IN THORACIC SURGERY*
}

\author{
Georges Cousineau, M D., F.F.A R.C.S , Leonard Legault, M.D., \\ and LEO FOREST, M.D.*
}

THE MAJOR PRINCIPLES of cardio-ı espiratory physiology have been known to us for a long time. However, many new ideas have been added to the classical principles. Anaesthesiology, a much younger science, has evolved in such a prodigious way in the last twenty years, that fev techniques of those early days are being used today For this reason, it appeared to us that it would be very interesting to review this evolution in a centre specializing in thoracic surgery. The centre in question is the Sacred-Heart Hospital of Montreal, with a bed capacity of 900 (of which 50 beds are allotted to thoracic surgery), which has been functioning for the past twenty-three years From 1935 to 1955, the authors of this paper have successively directed the Department of Anaesthesia of this hospital In this paper each author reports for the period when he was director.

\section{Dr Georges Cousineau, 1935-1945}

I shall discuss the Iron Age, from 1935 to 1945 My colleagues will report the єvolution in ôu techniques, its success being mdicated by the improved statistics. However, we must keep in mind that the type of patient submitted for thoracic surgery has changed.

Twenty years ago, who dıd we subject to thor acic surgery? Two kinds of patients:

1. The patients abandoned by all: carriers of nauseating bronchial secretions. The general status of these patients was poor because of the destructive processes $i_{1 i}$ the lungs. Morale was at its lowest Most patients asked for only one thing, namely, to get the operation over with as soon as possible

2. The tuberculous patient in the third phase, that is, the tuberculous patient with fibrous cavities. To prepare these patients fol surgery, we were limited to postural drainage, coramine, and digitaline Owing to the presence of abundant secretions, many patients had to be aspirated prior to the surgical procedure. This then gave a partial or temporarily dry bronchial field, but diminished considerably the general resistance of the patient The technique of bronchoscopic aspiration was very crude as compared with present procedures.

However the major principles of anaesthesiology were sufficiently known for thoracic surgery. Thoractomy is the opening of the pleural cavity which permits the atmospheric air to enter the pleural spaces. Therefore, three factors produce pulmonary collapse, namely, atmospheric pressure, the elasticity of the pulmonary tissue, and the abolition of the surface tension of the pleural spaces. Furthermore, as the equilibrium of the intrathoracic tension is abolished, there is danger of

\footnotetext{
'Presented at the Annual Meeting of the Canadian Anaesthetısts' Society of Toronto, Ontano, June 20-21-22, 1955

* Sacred-Heart Hospital, Montreal, P.Q.
} 
mediastmal shift and paradoxical respiration, producing progressive anoxia and contralateral infection We must further remember that in the diseased lur $g$ the vital capacity is reduced and abundant purulent secretions can spill from the diseased lung to the healthy one as the patient is lying on his healthy side durirg the operation. The operative technique is not to be neglected as the crudeness of the operation has been the cause of bronchiolar spasm and of nervous reflexes, producing a state of operative shock.

We did understand the importance of assisted pulmonary ventilation, but our technical methods at that tine seem elementary today.

There were two schools of thought on the conduct of anaesthesia. (a) The first called for a very light anaesthesia which preserved the cough reflex. This permitted the emptying of the bronchial tree but at the same time caused mediastınal shift and diminished vital capacity. High spinal anaesthesia and general anaesthesia with nitrous oxide with the open crrcurt fall into this category (b) The second method was deep anaesthesia with respirations assisted by the rlythmic compression of the anaesthetic bag This last school gradually developed the present status of intratracheal anaesthesia. The improvement of the instruments-laryngoscopes, intratracheal tubes-and the greater dexterity acquired by the anaesthetist in introducing intratracheal tubes added to the popularity of this technique

This was the era of general anaesthesia in a closed circuit Cyclopropane was makıng its début In Montreal, cyclopropane became popular thanks to the researches of Griffith, while in Boston, under the influence of Beecher, ether, nitrous oxide and oxygen, were favoured This was also the beginning of intravenous anaesthesia with the barbiturate evipal, and we used it in thoracic surgery As we review these first ten years of anaesthesiology for tharacic surgery, at Cartierville, we see a succession of techniques These different techniques icflect the efforts of the anaesthetist to maintain the principles of cardio-respiratory physiology In retrospect, from old records, the first intrathoracic intervention was very elementary However, today, we respect the courage, the tenacity, and the spirit of research of the pioneers in thoracic surgery

Today, we stress the team work of the surgeon, internist, 'and anaesthetıst. This also existed twenty years ago. In the early days the team worked together with one thought; the mechanical excision of an organ in record time From the study of these charts tarnished by time, and containing few details of the techniques employed, it is easy to comprehend the uneasmess and angurs of these workers and their tenacity in following therr task even though the results were very discouraging.

The first three intrathoracic interventions date back to 1934 All three were defeats. The surgical technique employed was the tourmquet applied at the pulmonary hilum The general anaesthesia was done with nitrous oxide-oxygen, an ordinary mask without "rebreathing" was used The pulse was recorded at threeminute intervals, but the blood pressure was rarely registered There was ro transfusion during the intervention, only an intravenous infusion. After the coropletion of the operation, a transfusion was given by the direct method. Time of the operation was from one to two and a half hous Two of these patients awakened, 
and were completely conscious one and a half hours after the operation, but unfortunately died the following day, owing to progressive anoxia and cardiac insufficiency. The third patient died on the operating table, forty minutes after the anaesthesia had begun. The surgical technique was identical, but a new anaesthetic method was employed, evipal given intravenously. Cause of death was overdosage with barbiturate, used for the first time in America.

Since 1935, the improvement in statistics has been progressive from year to year. During these 10 years, 1400 patients were submitted to thoracic interventions with a mortality rate of 5 per cent

We shall now mention two cases of that decade which are of particular interest

\section{1. $6-11-35$}

Yvette $B$, age 10, underwent a nght pneumonectomy for suppuratıve bronchiectasis. The surgical technique was the tourniquet applied to the pulmonary hilum, followed by complete excision of the lung. The time of operation was 1 hour and 43 minutes. The anaesthetic technique was sim le Nitrous oxide and oxygen was used with an ordinary mask without intratrachea intubation No transfusion, only intravenous' infusion, the pulse rate of 132-150 taken at intervals of 3 to 5 minutes, but no blood pressure recorded Excellent results, the patient leaving the hospital cured, two months after the intervention

\section{2. $20-9-40$}

Lucette D., age 2, brought to the operating room for right pneumonectomy for multiple pulmonary abscesses. Duration of operation, $2 \frac{1}{2}$ hours. The analesthesia, with intubation under direct vision, was done with cyclopropane and oxygen, blood pressure and pulse were recorded at 5-minute intervals $A$ transfusion of $100 \mathrm{cc}$. of 'citrated blood was given during the operation followed by a second transfusion of $175 \mathrm{cc}$. The endotracheal tube was borrowed from Dr. Griffth, who was always willing to help im rrove anaesthesia. The result was excellent, the child left the hospital two and one haf months a.ter the intervention, perfectly well

It is interesting to note the speed of the surgeons: for example, a thoracoplasty first stage took thirty minutes, second stage, twelve minutes. Also certain patients had as many as twelve interventions on the thorax, all of these within eighteen months.

In the years 1937-38, the technique was intratracheal anaesthesia with cyclopropane and oxygen in a closed circuit, the induction being done with evipal, later pentothal. The respirations were often assisted and sometmes completely controlled. And thus gradually we reached a new decade The work of the anaesthetist has improved as a result of the better understanding of the basic principles, the exchange of views, publications, and the acceptance of the principle of team work.

\section{Dr Leonard Legault, 1945-1950}

After long hesitant years in thoracic surgery, we have now arrived at a stage where success is finally attained with a period of more daring experiments. Working together, the anaesthetsst has greatly improved his techniques We are following in the steps of courageous pioneers who showed us the way to success by their studies and researches Operations both intra- and extra-thoracic grow 
every day in number and quality, and the success obtained is the result of a better co-operation between the surgeon and the anaesthetist

At present, the techniques most frequently employed are general anaesthesia with pentothal, cyclopropane, nitrous oxide and ether. Intratrachecl intubation is now a routine, since the use of curare, which renders it so easy, s now more familar. Intubation permits suction at any time during the operation and keeps the respiratory tract free of the secretions that may obstruct the respirc tory system, and in so doing, almost eliminates the dangers of atelectasis and of spreading infection.

For some time now, thoracic surgery has been improved by bronchoscopy, and as a result the patients who are to be operated on, have had their respiratory tract well prepared, and with far better results than with postural drainage. We must also add that the patients are better selected and have received better preoperative care. Cardio-respiratory physiology has permitted a more complete study of the patients and, as a result, the thoracic surgeon works under more favourable conditions for himself and the patients

It was during the period under review that our attention was focused on epidural anaesthesia, which was described by Fugihama, Neves, Brasler and Buckungham in the Journal of Thoracic Surgery for February 1948

The solution employed was 30 to $40 \mathrm{cc}$. of novocaine and cobefrine $1 / 2000,000$ to which we added 10 to $15 \mathrm{mgm}$ of pontocaine to produce a longer lasting anaesthesia

We have used this method for poor risk patients, to avold the danger of spreading infection, and in patients who had previous thoraco-plastic surgery, and had a reduced cardiac, renal, and respiratory capacity. The results obtained proved without doubt the importance of epidural anaesthesia for certain indicated cases

Patients operated on for thoracoplasty, 1st stage

26

Patients operated on for thoracoplasty, 2nd and 3rd

82

Perfect anaesthesia without supplementation $70 \%$

Good anaesthesia with pentothal in I.V. solution $25 \%$

Poor anaesthesia with addition of 'pentothal and nitrous oxide $5 \%$

This series was without a death or serıous accident, and we may say that epidural anaesthesia was of great help in the worst cases, since it makes perfect oxygenation possible during the entire operation, and also prevents postoperative atelectesia.

We shall now end this part of the symposium by giving you the general statistics in thoracic surgery for the years 1945 to 1950:

\begin{tabular}{lrrrrr} 
Years & No of operations & Intra-thoracic & Extra-thoracic & Death & \% \\
\hline 1945 & 300 & 69 & 211 & 15 & 5 \\
1946 & 332 & 105 & 227 & 14 & $41_{2}$ \\
1947 & 356 & 133 & 223 & 13 & 36 \\
1948 & 385 & 132 & 253 & 10 & 26 \\
1949 & 300 & 82 & 218 & 5 & 1.66 \\
1950 & 407 & 75 & 332 & 6 & 1.4
\end{tabular}


You may therefore judge for yourself the progress constantly made in thoracic surgery; without being boastful about it, we believe the anaesthetists were of great help. A few words from Dr G. A. P. Hurley may perhaps be quoted here: "If thoracic surgery has made so much progress in the last twenty years, it is only with the help of the anaesthesia group, who have made successful those new modern methods of anaesthesia."

\section{Dr Leo Forest, 1950-1955}

Today, the Department of Anaesthesiology of the Sacred-Heart Hospital is getting constant help from a full-time internist. Our department is also working in close co-operation with the department of cardio-respiratory physiology of the Lavoisier Institute All patients facing a major thoracic operation are first thoroughly investigated by a group of specialists in respiratory functions at this Instutute. Following this, a consultation between the surgeon, the anaesthetist and the internist is required before the operation The method of anaesthesia and the position of the patient on the operating table are decided durmg this consultation The internist then takes over for the entire pre- and postoperative period

Thoracic surgery requires closer supervision on the part of the anaesthetist than any other surgery. Therefore, the technique used must be as simple as possible. In a case of bronchiectasis we use either bronchial intubation with a Carlens' tube or the two-tube method, one in the left bronchus and the other in the right In a case of external bronchial fistula we use bronchial intubation. Our anaesthetists are tramed in bronchoscopy and the aspuration of patients just before intubation.

For patients with emphysema, the orotracheal tube permits light anaesthesia which in turn allows better control of the electrolytic balance This is very important in all cases of pulmonary emphysema

For a time we made use of an automatic ventilation unit, but we have discontinued this. It was too difficult to synchronize the system with the spontaneous breathing of the patient

For induction, we use barbiturates and mantenance is carried out with nitrous oxide, ether, and cyclopropane. Good anaesthesia for thoracic surgery means perfect control over respiration and circulation

Though unobstructed respiration is important durmg any kind of operation, it is without any doubt much more important during operations where the lungs and the heart are manipulated by the surgeons' hands. Pulmonary ventilation must be adequate for the mantenance of normal oxygen and carbon dioxide blood levels.

As for circulation, the anaesthetist must always bear in mind that the normal negative thoracic pressure helps greatly the return of blood to the right heart during inspiration. When the thoracic cavity is open, this mechanism does not work any more and the filling of the right heart is slowed. Moreover, the surgeon is manipulating areas of great nervous reflex activity It is up to the anaesthetist to control, to decrease, or to inhibit completely these reflexes For this, he may have to use atropine, novocaine, physostigmine, or curare according to 
the situation. These diugs are to control the unwanted reflexes of sympathetic or parasympathetic nervous systems.

It is needless to say that most thoracic operations mean considerable blood loss for the patient. We have adopted the system of weighing sponges. Though simple, this system is the most accurate way of figuring how much blood to give the patient during and after the operation.

The noted improvement in the statistics of the department of thoracic surgery shows the necessity of close co-operation in hospital work. The mortality rate of the department is now 0.8 per cent as compared with 6 per cent only a few years ago

This improvement is the result of better surgical technique, better hospital equpment, and, above all, better anaesthesia because the anaesthetist understands cardio-respuratory physiology.

\section{SUMMARY}

The authors have been, in succession, durectors of the Department of Anaes thesiology of the Sacred-Heart Hospital of Montreal for the past twenty years. They have combined in this paper io outline the evolution of anaesthesia over this period in the thoracic surgery unit of this hospital 